\title{
Child Abuse: A Complex Case Report: Association of Amitriptyline Intoxication and Shaken Baby Syndrome
}

\section{Grenier $\mathrm{F}^{1 *}$, Paysant $\mathrm{F}^{1}$, Durand $\mathrm{C}^{2}$, Eysseric $\mathrm{H}^{3}$, Bost-Bru $\mathbf{C}^{4}$ and Scolan $\mathbf{V}^{1}$}

${ }^{1}$ Department of Forensic Medicine, University Grenoble Alpes, France

${ }^{2}$ Department of Paediatric Radiology, University Grenoble Alpes, France

${ }^{3}$ Department of Forensic Toxicology, University Grenoble Alpes, France

${ }^{4}$ Department of Pediatrics, University Grenoble Alpes, France

\begin{abstract}
This article concerns the unusual association between two kinds of mistreatment: Shaken baby Syndrome/ Abusive Head Trauma (SBS/AHT) and intentional intoxication by a tricyclic antidepressant (TCA) (amitriptyline)

A six-month-old girl was hospitalized in state of coma after several episodes of malaise. The ophthalmologic exams found bilateral retinal and retrohyaloid hemorrhage, the RMI detected non-compressive subdural hematomas localized in the posterior fossa and the brain convexities and the toxicological results were positive for amitriptyline $(99.4 \mu \mathrm{g} / \mathrm{L})$ and its metabolite nortriptyline $(154 \mu \mathrm{g} / \mathrm{L})$ in the blood. All differential diagnoses were eliminated such as glutaric aciduria II, copper metabolism anomaly, and Osteogenesis Imperfecta. The police investigation reports the grand-mother and the father had an amitriptyline prescription.

The toxicological analysis of the hair of the baby girl and of the parents was very useful to prove the chronical exposure. A scientific review identified few cases reports of child amitriptyline intoxication and among us, none of them enabled to compare our findings. Our description of this fact is very complete, with decrease concentration table of amitriptyline in the infant blood, permitting the comparison with another future cases. All these data confirm a singular case of Shaken baby Syndrome/Abusive Head Trauma and intentional intoxication association. This entity is not describe in the literature and poses a lot of questions especially the obligation to perform systematic toxicological analyses in case of SBS/AHT.
\end{abstract}

Keywords: Child abuse; Migraine; Neuropathic pain; Infant intoxication

\section{Introduction}

This article reports a unique case of child abuse associating Shaken baby Syndrome/Abusive Head Trauma (SBS/AHT) with intentional intoxication. In our case, the drug used was amitriptyline. This medication is a Tricyclic Antidepressant (TCA) and can be used in case of depression and other disorders such as nocturnal enuresis, attention deficit hyperactivity syndrome, migraine headaches and neuropathic pain in adults and children from 6 years of age. It is not an infant prescription [1]. Unfortunately, intoxication in child abuse is not rare. In 2012, it was reported that children under 3 years of age were concerned in $35.7 \%$ of exposures and children younger than 6 years accounted for approximately half of all human exposures (48.4\%) [2]; among them, 1348 cases of intentional intoxication with 1 abuse fatality case in 1,102,307 intoxications were reported in children under 5 years old in 2012 [2]. Despite the number of registered cases, we found few cases with full clinical and toxic description of infant intoxication by amitriptyline in the scientific literature. We were not able to compare the rate of amitriptyline for infants because at the time of this study, there are no such references. The association of sedative drug intoxication and SBS/AHT has not been ever reported (we haven't found any other case described in the scientific literature). In this article, we expose complete clinical and toxicological descriptions.

\section{Case Report}

A six-month-old girl was hospitalized for the first time for a break in the weight curve ( $8 \%$ of weight loss), a decrease for appetence in baby bottles, stereotyped movements and stridor. The anamnesis revealed episodes of malaise with generalized hypotonia or hypertonia, paleness, redness of the cheeks, chewing and patterns of movement disorders of the two hands. The baby didn't have any past medical history or treatment. The laryngomalacia diagnosed by the otolaryngologist was not responsible for the previous clinical symptoms. The neurologist who performed an electroencephalogram during a crisis identified by the mother concluded to the absence of pathological waves. The biological analyses (plasmatic and urinary ionogram, dosage of free catecholamines, and methyl derivatives in the serum) were normal.

The baby was discharged after a good appetite and an increase in weight.

Ten days after, the child was hospitalized again as an emergency in a state of coma with mydriasis. According to the mother, after a diaper change, the baby girl had a brutal malaise with generalized hypotonia. She arrived at the hospital with a Glasgow score of 3 and respiratory pauses. After mask ventilation, the Glasgow score increased to 9. Later, she presented a generalized tonic-clonic seizure and was intubated and ventilated with injection of Fosphenytoin, Diazepam, Atropine, Ketamine, Propofol, Cisatracurium besilate, Midazolam, Sufentanil citrate. Two MRIs, realized in 8 days apart, revealed to J1 a non-compressive subdural hematomas localized in the posterior fossa (at this time, there is no abnormality of cortex signal on diffusion sequence) and to J8 a non-compressive subdural hematomas of the brain convexity and cortical laminar necrosis in the bilateral parietal posterior and occipital lobes (Figure 1). The ophthalmologic exam concluded a bilateral retinal and retrohyaloid hemorrhage. No external trauma was found in the clinical exam.

${ }^{*}$ Corresponding author: Florian Grenier, Department of Forensic Medicine, University Grenoble Alpes, France, Tel: 0476768470; E-mail: fgrenier1@chu-grenoble.fr

Received September 07, 2015; Accepted October 02, 2015; Published October 09, 2015

Citation: Grenier F, Paysant F, Durand C, Eysseric H, Bost-Bru C, et al. (2015) Child Abuse: A Complex Case Report: Association of Amitriptyline Intoxication and Shaken Baby Syndrome. J Clin Case Rep 5: 617. doi:10.4172/2165-7920.1000617

Copyright: (๑) 2015 Grenier F, et al. This is an open-access article distributed under the terms of the Creative Commons Attribution License, which permits unrestricted use, distribution, and reproduction in any medium, provided the original author and source are credited. 


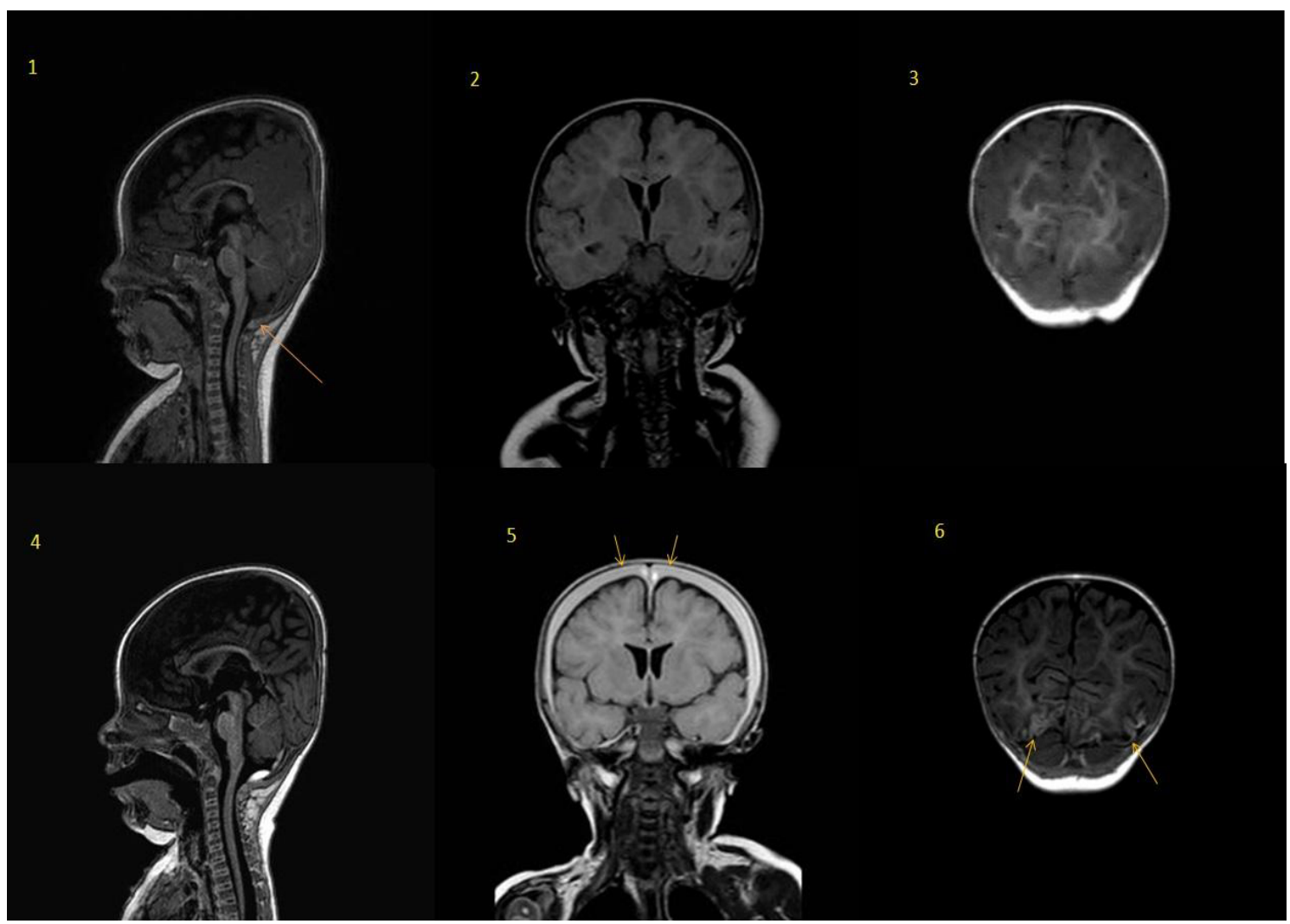

Figure 1: MRI performed during the second hospitalization showing:

MRI to J 1: image 1 : sagittal T1W shows isointense subdural hematoma. Image 2 : frontal Flair MR shows a hyperintense bitemporal subdural collection. Image 3 : Frontal T1W shows no cortical abnormality

MRI to J 8: image 4 : sagittal T1W shows hyperintense subdural hematoma. Image 5: frontal Flair MR shows a hyperintense bihemispheric subdural collection. Image 6: Frontal T1W shows occipital cortical necrosis

Following this finding, blood analyses were performed, and the toxicological results were positive for amitriptyline $(99.4 \mu \mathrm{g} / \mathrm{L})$ and its metabolite nortriptyline $(154 \mu \mathrm{g} / \mathrm{L})$ in the blood. The viral and bacterial biological analyses were normal, and the hypotheses of glutaric aciduria II, copper metabolism anomaly, and Osteogenesis Imperfecta were eliminated. The EKG controls were without anomaly. From a clinical point of view, it was noted that epileptoid trepidations persisted with reflexes more active than normal in the lower limbs, absence of eye tracking, and high blood pressure during the first 48 hours. The child was extubated one day after her hospitalization, and the anti-epileptic treatment was stopped four days later.

The neurologic exams performed at that time revealed a clinical stability with persistence of epileptoid hypertonia of the lower limbs evocative of a pyramidal syndrome, fast osteotendinous reflexes, absence of eye tracking and contact, no light reaction (sign of blindness), and cervical hypotonia. The bilateral retrohyaloid hemorrhage was stabilized after 10 days of hospitalization.

Three electroencephalograms were performed, one of which was video recorded. All three electroencephalograms were normal, even when the camera recorded an event of malaise.

After elimination of other possible diagnoses such as Congenital and acquired coagulation disorders, Cerebral arteriovenous malformation, Metabolic diseases (glutaric aciduria, Menkes syndrom), Osteogenesis imperfect, according to the HAS recommendation, we concluded that the retinal and cerebral lesions corresponded to the Shaken Baby
Syndrome [3].

The baby girl had to be operated on her ocular lesions because of the retinal and retrohyaloid lesions. It must be noted that the external examination or the X-Ray of the entire body didn't reveal any physical mistreatment associated to the identified lesions.

\section{Toxicological analyses}

Toxicological urine screenings were performed using liquid chromatography coupled to a diode array detector (LC-DAD) and gas chromatography coupled to mass spectrometry (GC-MS). Because of the small quantity of the collected samples, the blood screening was performed using only LC-DAD.

The urine screenings revealed the presence of drugs which had been administered during the medical care (phenytoin, ketamine, propofol, diazepam and its metabolites) and the blood concentrations of Amitriptyline and Nortriptyline decreased during the hospitalization of the infant (Table 1) [3].

Hair analysis was ordered by the judge for the baby and his parents to check if the drug exposure was chronic. The presence of an antidepressant drug and its metabolite was investigated in the hair using the LC-MS/MS method. Those samples were collected on the baby girl, 1 day after the second hospitalization as well as 5 weeks later. Two hair specimens from patients treated with AMI were analyzed confirming the accuracy of the method. Despite the interpretation difficulties, an 


\begin{tabular}{|c|c|c|c|c|}
\hline Plasma concentration & First day & Second day & Fourth day & Sixth day \\
\hline Amitriptyline $(\mu \mathrm{g} / \mathrm{l})$ & 99.4 & 58.0 & 13.6 & 6.5 \\
\hline Nortriptyline $(\mu \mathrm{g} / \mathrm{l})$ & 154 & 129 & 53 & 5 \\
\hline
\end{tabular}

Table 1: Blood concentration of Amitriptyline and Nortriptyline during the second hospitalization.

\begin{tabular}{|c|c|c|}
\hline Segment (cm) & AMI $\mathbf{( n g} / \mathbf{m g})$ & NOR $\mathbf{( n g} / \mathbf{m g})$ \\
\hline $0-0.5$ & 6.89 & 8.14 \\
\hline $0.5-1.0$ & 6.65 & 7.12 \\
\hline $1.0-2.5$ & 8.97 & 8.96 \\
\hline $2.5-4.0$ & 9.69 & 8.93 \\
\hline
\end{tabular}

Table 2: Data analysis of the first strand of the baby (one day after the second hospitalization).

\begin{tabular}{|c|c|c|}
\hline Segment $(\mathbf{c m})$ & AMI $\mathbf{( n g} / \mathbf{m g})$ & NOR $(\mathbf{n g} / \mathbf{m g})$ \\
\hline $0-0.7$ & 1.19 & 3.60 \\
\hline $0.7-1.2$ & 1.41 & 4.00 \\
\hline $1.2-1.9$ & 1.18 & 3.28 \\
\hline $1.9-2.5$ & 0.79 & 2.35 \\
\hline $2.5-3.0$ & 0.65 & 1.82 \\
\hline $3.0-3.6$ & 0.59 & 1.49 \\
\hline $3.6-5.0$ & 0.54 & 1.26 \\
\hline
\end{tabular}

Table 3: Data analysis of the second strand of the baby collected 5 weeks after the discovery of the amitriptyline intoxication.

external contamination by sweat was rejected and the result showed regular and repeated exposure to amitriptyline concerning the baby girl (Tables 2 and 3) [4-6].

The anamneses revealed that the grand-mother and the father were taking Amitriptyline. However, the toxicological hair analysis of the two parents was negative.

\section{Discussion}

This case report is very unique from many points of view. Firstly, clinically, because of the difficulties in diagnosing the association of SBS/AHT and TCA. Secondly, important challenging forensic issues were raised: were there one or many abusers? What were the symptoms and the consequences of each abuse? Must we perform toxicological analyses for each abused child?

\section{Amitriptyline intoxication}

Firstly, the amitriptyline is never prescribed to infants and there aren't any concentration charts of the molecule in baby blood to quantify the degrees of intoxication of the baby girl, and the initial administered quantity from the blood concentration analysis.

Secondly, intoxication by amitriptyline is not rare. The American association of poison control centers reported 430 cases of amitriptyline intoxication in 2012 [2] and 996 cases of intentional ingestion of amitriptyline in children under 6 years old in 2002 including one fatal case [7].

Thirdly, it is important to note that between 2000 and 2008 in the USA; at least one sedating drug was detected in 17 out of the 18 infant deaths listed. The use of a sedating agent was 3.6 times more likely to be associated with death or a major outcome [8].

\section{What do we know about amitriptyline intoxication?}

In case of overdosage, symptoms may include antimuscarinic effects, including dryness of the mouth, hot dry skin, dilated pupils, tachycardia, urinary retention, and intestinal stasis associated to excitement and hyperactivity. Severe symptoms include unconsciousness, convulsions and myoclonus, hyper reflexia, hypothermia, hypotension, metabolic acidosis and respiratory and cardiac depression. Cardio toxicity can occur with arrhythmias, conduction defects (QT prolongation) and hypotension [9-13]. According to Olgun, toxicity occurred at doses greater than $10 \mathrm{mg} / \mathrm{kg}$ for 54 children poisoned by amitriptyline. The symptoms revealed lethargy (79.9\%), sinus tachycardia $(57.7 \%)$ and coma (48.1\%)., Hyponatremia (26.9\%) and leukocytosis (25\%) were detected via biological analyses [2].

Woolf affirms that in more than 60 published pediatric reviewed case reports with tricyclic antidepressant poisoning, symptoms occurred at doses as low as $3 \mathrm{mg} / \mathrm{kg}$. Concerning amitriptyline intoxication, $50 \mathrm{mg} /$ $\mathrm{kg}$ is the lowest ingestion associated with mild toxicity and $15 \mathrm{mg} / \mathrm{kg}$ corresponds to the lowest dose associated with death. A single case of $325 \mathrm{mg}(16 \mathrm{mg} / \mathrm{kg})$ nortriptyline ingestion by a 4 -year-old resulted in severe toxicity [7]. One fatal case of acute malicious exposure to amitriptyline of a 3-year-old was reported to the Annual report of the American Association of Poison Control Centers in 2002. The blood analyses revealed that the dosage of amitriptyline was: $4.600 \mu \mathrm{g} / \mathrm{L}$ and nortriptyline: $2.900 \mu \mathrm{g} / \mathrm{L}$ [7].

Thus, the amitriptyline intoxication is not rare but scientific literature reports mainly acute and accidental intoxication contrary to our case which is a chronic and voluntary intoxication. Symptoms can occur with low dosage intoxication which can be mortal.

\section{Evolution and Complications}

According to scientific reviews, the cerebral lesion met in SBS/ AHT can cause many after-effects such as severe to moderate handicap in more than $50 \%$ of the cases, post-trauma epilepsy, cerebral atrophy, and intellectual deficit [14-18]. The after-effects of amitriptyline intoxication are not defined, but the scientific literature suggests a favorable clinical evolution $[10,11,19]$.

\section{Association of Intoxication and SBS/AHT}

It was difficult to individualize and identify whether the symptoms were due to intoxication or to the SBS/AHT (namely: behavioural change, vomiting, respiratory pause, paleness, a baby in pain [9]. As the SBS/AHT symptoms are nonspecific, we didn't diagnose any cardio toxicity or antimuscarinic effect in favor of intoxication by amitriptyline in the clinical exams of this baby. Indeed, the systematic toxicological analyses permitted to detect the association of two types of abuse.

Furthermore, we haven't found any link associating amitriptyline intoxication and cerebral lesions with laminar necrosis in the scientific literature.

This association, especially the intoxication by a sedative agent and SBS, is unusual, thus, not described in the scientific literature. Surely, as Yin et al reported [20], a conjunction of poisoning with other forms of abuse is possible. In 1982, Dine and Mc Govern discovered that in 41 cases of abuse poisoning, seven were associated with physical abuses [12]. In 2008, Yin found that among 6 cases of fatal poisoning from malicious use of cough/cold medicine, 3 cases were associated with physical abuse. There is no reported case on the association of SBS and poisoning abuse and how they are linked to the abusers profiles. Multiples causes of child poisoning abuse exist and one of them consists in sedating a baby to make him/her stop crying [20]. Despite 
the absence of report on their association, SBS/AHT and intoxication by a sedating agent can be part of the same entity of child abuse. Alternatively, a physically abused baby is likely to be more irritable than usual thus; the perpetrator would wish to sedate the infant after an inflicted injury [8]. The absence of case associating SBS and sedating drugs poses the following questions:

-Would it be more detectable, if we performed toxicological analyses for each SBS case?

-Could the rarity of this case reveal the unusual act of two different abusers (one using a sedating drug and the other shaking the baby)?

-Or, is it a case of Munchhausen Syndrome by Proxy?

Unfortunately, we cannot answer these questions but we think that systematic toxicological analyses can allow diagnosing the association of voluntary intoxication and physical mistreatment.

\section{Conclusion}

This case report revealed a rare case of mistreatment namely the association of SBS/AHT with a sedative drug (amitriptyline) and the importance of toxicology in the case of SBS/AHT because of the nonspecific and plural symptoms.

Furthermore, the toxicology analysis of the baby's hair, despite the difficulties in interpreting the results, was very conclusive to prove the chronic exposure to the substance and eliminate the accidental nature of the intoxication as it is usually reported by the aggressor. The description of this case allows comparison with possible future cases.

\section{References}

1. Sweetman SC, Martindale (2009) The Complete Drug Reference. (36thed). Pharmaceutical Press 376.

2. Mowry J, Spyker DA, Cantilena LR, Bailey JE, Ford M (2013) 2012 Annual report of the American Association of Poison Control Centers Toxic Exposure Surveillance System. Clinical Toxicology 51: 949-1229.

3. Allibe N, Eysseric-Guerin H, Kintz P, Bartoli M, Bost-Bru C, et al. (2015) Amitriptyline poisoning of a baby: how informative can hair analysis be? Forensic Sci Int 249: 53-58

4. Hill V, Loni E, Cairns T, Sommer J, Schaffer M (2014) Identification and analysis of damaged or porous hair. Drug Test Anal 6 Suppl 1: 42-54.
5. Kintz $\mathrm{P}(2012)$ Segmental hair analysis can demonstrate external contamination in postmortem cases. Forensic Sci Int 215: 73-76.

6. Watson WA, Litovitz TL, Rodgers GC Jr, Klein-Schwartz W, Youniss J, et al (2003) 2002 annual report of the American Association of Poison Contro Centers Toxic Exposure Surveillance System. Am J Emerg Med 21: 353-421.

7. Woolf AD, Erdman AR, Nelson LS, Caravati EM, Cobaugh DJ, et al. (2007) Tricyclic antidepressant poisoning: an evidence-based consensus guideline for out-of-hospital management. Clin Toxicol (Phila) 45: 203-233.

8. Bonnier C (2009) Children become victims of Abusive Head Trauma. Arch Pediat 13: 528-533.

9. Caksen H, Akbayram S, OdabaÄŸ D, Ozbek H, Erol M, et al. (2006) Acute amitriptyline intoxication: an analysis of 44 children. Hum Exp Toxicol 25: 107-110.

10. Clement A, Raney JJ, Wasserman GS, Lowry JA (2012) Chronic amitriptyline overdose in a child. Clin Toxicol (Phila) 50: 431-434.

11. Dine MS, McGovern ME (1982) Intentional poisoning of children--an overlooked category of child abuse: report of seven cases and review of the literature. Pediatrics 70: 32-35

12. Olgun H, Yildirim ZK, Karacan M, Ceviz N (2009) Clinical, electrocardiographic, and laboratory findings in children with amitriptyline intoxication. Pediatr Emerg Care 25: 170-173.

13. Doherty S, Cave G, Harvey M (2012) Paediatric amitriptyline overdose. Open Journal of Pediatric 2: 170-174.

14. Duhaime AC, Christian C, Moss E, Seidl T (1996) Long-term outcome in infants with the shaking-impact syndrome. Pediatr Neurosurg 24: 292-298.

15. Lak NS, Malingre MM, Hogeman PH (2012) Amitriptyline cream ingestion in a 1-year-old boy. Pediatrics 130: e1030-1033.

16. Laurent-Vannier A, Toure H, Vieux E, Brugel DG, Chevignard M (2009) Longterm outcome of the shaken baby syndrome and medicolegal consequences: a case report. Ann Phys Rehabil Med 52: 436-447.

17. Lo TY, McPhillips M, Minns RA, Gibson RJ (2003) Cerebral atrophy following shaken impact syndrome and other non-accidental head injury (NAHI). Pediatr Rehabil 6: 47-55.

18. Deegan C, O'Brien K (2006) Amitriptyline poisoning in a 2-year old. Paediatr Anaesth 16: 174-177.

19. http://www.has-sante.fr/portail/upload/docs/application/pdf/2011-09/ syndrome_du_bebe_secoue_-_recommandations_de_la_commission_d_ audition.pdf

20. Yin S (2010) Malicious use of pharmaceuticals in children. J Pediatr 157: 832 836. 